\title{
Knockdown of RhoGDIa induces apoptosis and increases lung cancer cell chemosensitivity to paclitaxel
}

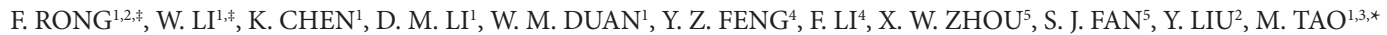

${ }^{1}$ Department of Oncology, the First Affiliated Hospital of Soochow University, Suzhou, Jiangsu 215006, China; ${ }^{2}$ Cancer Center, Lu'an Affiliated Hospital of Anhui Medical University, Lu'an, Anhui 237000, China; ${ }^{3}$ Institute of Medical Biotechnology, Soochow University, Suzhou, Jiangsu 215021, China; ${ }^{4}$ Department of Pathology, the Second Affiliated Hospital of Soochow University, Suzhou, Jiangsu 215006, China; ${ }^{5}$ School of Radiation Medicine and Public Health, Soochow University, Suzhou, Jiangsu 215006, China

${ }^{*}$ Correspondence: mtao@medmail.com.cn

"These authors contributed equally to this work.

Received December 26, 2011 / Accepted April 2, 2012

\begin{abstract}
This study aimed to investigate the effects of RhoGDIa knockdown on apoptosis and the chemosensitivity of lung cancer cells to paclitaxel. The signaling proteins involved were also assessed. RhoGDIa expression was assessed by RT-PCR, Western blotting and immunohistochemistry. Apoptosis was determined by flow cytometric assessment, and cell viability was measured with the MTT assay. Phosphorylation levels of signaling proteins, ERK, JNK, Akt, Bad and IkBa were tested by Western blotting and immunohistochemistry. Positivity for RhoGDIa in lung cancer tissues was significantly higher than in paracancerous tissues. Downregulation of RhoGDIa was associated with significantly increased apoptosis and repressed cell viability. This effect could be due to the consequent upregulation of p-JNK, as well as decreased levels of p-ERK, p-Bad and $\mathrm{p}-\mathrm{I} \kappa \mathrm{Ba}$. Knockdown of RhoGDIa strengthened the effect on apoptosis and inhibition of cell viability induced by paclitaxel treatment. This chemosensitization effect could be a result of the intensification of pro-apoptotic JNK activation, and repression of anti-apoptotic p-ERK, p-Bad and p-IкB $\alpha$ expression stimulated by paclitaxel. In summary, our study indicated that RhoGDIa could be a promising therapeutic target, and the combination of RhoGDIa siRNA and paclitaxel might be a valuable potential therapy for lung cancer treatment.
\end{abstract}

Key words: lung cancer, RhoGDI $\alpha$, apoptosis, chemosensitivity

Lung cancer is the one of the leading cause of cancer-related deaths worldwide with less than $16 \%$ of patients surviving beyond 5 years $[1,2]$. Cytotoxic chemotherapy remains the key component of treatment in both the adjuvant and metastatic settings. However, many patients do not respond to chemotherapy. Therefore, new treatment modalities against this aggressive neoplasm are urgently needed.

Rho proteins, a group of small guanosine triphosphate (GTP)-bound proteins, have been shown to be involved in a variety of fundamental cellular processes, including mitosis, intracellular transport, cytoskeletal rearrangement and cell morphogenesis. The Rho GDP dissociation inhibitor (RhoGDI) is a cellular regulatory protein that acts primarily by controlling the cellular distribution and activity of Rho GTPases. As one of three GDIs indentified as being specific for the Rho proteins, RhoGDIa is ubiquitously expressed in a variety of tissues. RhoGDIa is known to function as a GDI for Rac and involved in various fundamental cellular processes [3].

RhoGDIa is often thought of as a negative regulator of the Rho GTPases, as it has the ability to bind and hold the GTPases in inactive, cytosolic forms that are unable to interact with guanine-nucleotide exchange factors (GEFs) effectively, and/or other downstream target molecules. However, there is evidence that RhoGDIa can also positively regulate RhoGTPases $[4,5]$. For example, RhoGDIa positively regulates Racl by protecting it from apoptosis-associated inactivation [5]. Therefore, the function of RhoGDIa is yet to be fully established.

It has been shown that RhoGDIa is frequently upregulated in ovarian and breast cancers [6-8]. Overexpression of RhoGDIa protects cancer cells from the induction of apoptosis and plays a role in chemotherapy drug resistance $[5,9,10]$. Nonetheless, the expression of RhoGDIa in lung cancers and 
the mechanism underlying the action of RhoGDIa as an antiapoptotic molecule have not yet been elucidated.

In this study, we measured the expression of RhoGDIa in lung cancer tissues. The anti-apoptotic and chemoresistant effects of RhoGDIa were tested in the A549 lung cancer cell line. The effects on related cell signaling pathways were also investigated.

\section{Patients and methods}

Patient specimens and characteristics. Surgical specimens from human lung tumors were collected from 40 patients who attended our hospital. All human tissue samples were obtained and handled in accordance with an approved Institutional Review Board application (the Committee on Medical Ethics, the First Affiliated Hospital of Soochow University). All samples were collected before any chemotherapy or radiotherapy had been given. Samples of normal tissue from areas distant to the tumor or tissue taken from adjacent to the tumor were available from $75 \%$ of the patients. Each specimen was fixed in $10 \%$ formalin and embedded in paraffin, before $4-\mu \mathrm{m} \mathrm{sec}-$ tions were cut and stained with hematoxylin and eosin for the assessment of tumor morphology. Two pathologists evaluated the tumors. There were 18 squamous cell carcinomas, 16 adenocarcinomas, and six small-cell lung carcinomas (SCLC). Tumor histopathological grading was performed according to the WHO grading system: two cases were well differentiated, 20 cases showed intermediate levels of differentiation and 18 cases were poorly differentiated. Tumor stage was determined according to the tumor-node-metastasis staging system (TNM, $6^{\text {th }}$ edition). Nine cases were identified as stage I, 18 as stage II, 12 as stage III and one case was stage IV. The mean age of patients at the time of primary surgery was $61.8 \pm 8.4$ years (range, 39-80 years).

Antibodies. The polyclonal antibodies used in this study were sc-360 to detect RhoGDIa (Santa Cruz Biotechnology, Santa Cruz, CA, USA), ab8932 to detect p-ERK and ab28825 to detect p-Bad (Abcam PLC, Cambridge, UK). The monoclonal antibodies used were anti-p-IкBa (B-9) and anti-p-JNK (G-7; Santa Cruz Biotechnology).

Immunohistochemical staining. Immunohistochemical (IHC) staining was performed on $4-\mu \mathrm{m}$ sections of formalin-fixed, paraffin-embedded tissues. Samples were heated at $56^{\circ} \mathrm{C}$, deparaffinized, and rehydrated through a graded series of ethanol. Endogenous peroxidase was blocked with 3\% hydrogen peroxide in methanol for $10 \mathrm{~min}$. Microwave antigen retrieval was performed for $\mathrm{p}$-I $\mathrm{I} B \alpha$; heat-mediated antigen retrieval for other antibodies, followed by incubation with the primary antibody for 1 hour at room temperature. After incubation with the corresponding secondary antibodies for $20 \mathrm{~min}$, the bound complex was visualized by using the SuperPicTure polymer detection kit (No.87-8963; Invitrogen). The fetal kidney was used as a positive control. Negative controls were prepared by using phosphate-buffered saline (PBS) as a substitute for the primary antibody.
Evaluation of immunostaining. Immunostaining was independently evaluated by two pathologists who were blinded to the clinicopathological findings of the patients. Staining intensity was scored between given a score of 0 and -3 for negative, weak, moderate, or strong staining, respectively. The distribution was scored as $0-4$ for staining distributions of $0 \%,<10 \%, 10-50 \%, 50-90 \%$, and $>90 \%$, respectively. The sum of these scores was then used to determine four groups as follows: (I) negative $=0-1$, (II) weak $=2-3$, (III) moderate $=4-5$, and (IV) strong $=6-7$. A total score of between 4 and 7 indicated positive immunostaining [11].

Cell culture. The human lung cancer cell lines, A549 and H157, were purchased from the American Type Culture Collection (Manassas, Virginia, USA). Cells were cultured at $37^{\circ} \mathrm{C}$ in Dulbecco's modified Eagle's medium (Invitrogen, Camarillo, CA, USA) containing 10\% fetal bovine serum (Invitrogen), $100 \mathrm{U} / \mathrm{mL}$ penicillin and $100 \mu \mathrm{g} / \mathrm{mL}$ streptomycin. The cell line was incubated in a humidified atmosphere of $95 \%$ air and $5 \% \mathrm{CO}_{2}$.

Transfection of small interfering RNA. Target-specific small interfering RNA (siRNA; sc-36417) designed to knock down RhoGDIa gene expression, irrelevant (Control) siRNA (sc-37007), and the transfection medium (sc-36868), were purchased from Santa Cruz Biotechnology. SiRNA transfections were performed according to the instructions of the manufacturer.

Reverse transcription-polymerase chain reaction. The quantification of gene expression was performed by reverse transcription-polymerase chain reaction (RT-PCR) using an Eppendorf PCR system (Eppendorf, Hamburg, Germany). cDNA was made from total RNA extracted from cultured A549 cells. The following primers were designed to span exon-intron junctions: RhoGDIa, 5'-CAGATTGCAGCGGAGAACGAG-3' (forward), 5'ATGTACTTCATGCCGGACA-3' (reverse); GAPDH, 5'-CAACTACATGGTCTACATGTTCC-3' (forward), 5'CAACCTGGTCCTCAGTGTAG-3' (reverse). The products of the RT-PCR reaction were electrophoresed on $1 \%$ agarose gels, visualized by ethidium bromide staining, and quantified using Quantity One software (Bio-Rad Laboratories, Hercules, CA, USA). Each sample was normalized against GAPDH mRNA expression.

Western blot analyses. Cells were collected in the log phase and lysed with $100 \mu \mathrm{L}$ PIPA lysis buffer. Protein $(50 \mu \mathrm{g})$ from the lysate was electrophoresed in $10-15 \%$ sodium dodecyl sulfate polyacrylamide gel and transferred to a polyvinylidene difluoride immobilon P membrane (Millipore, Bedford, MA, USA) according to the instructions of the manufacturer. Membranes were probed with the previously detailed antibodies and anti- $\beta$-actin (Cell Signaling, Beverly, MA, USA). The protein expression was determined using horseradish peroxidase-conjugated antibodies followed by enhanced chemiluminescence (ECL Amersham Pharmacia Biotech, Buckinghamshire, UK) detection, and further quantified using Quantity One software (Bio-Rad Laboratories). 

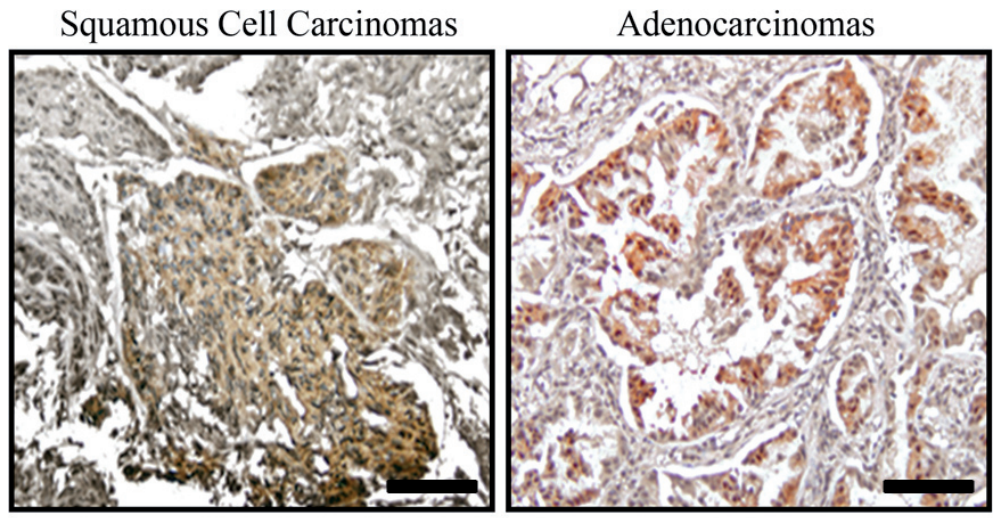

Small Cell Carcinomas
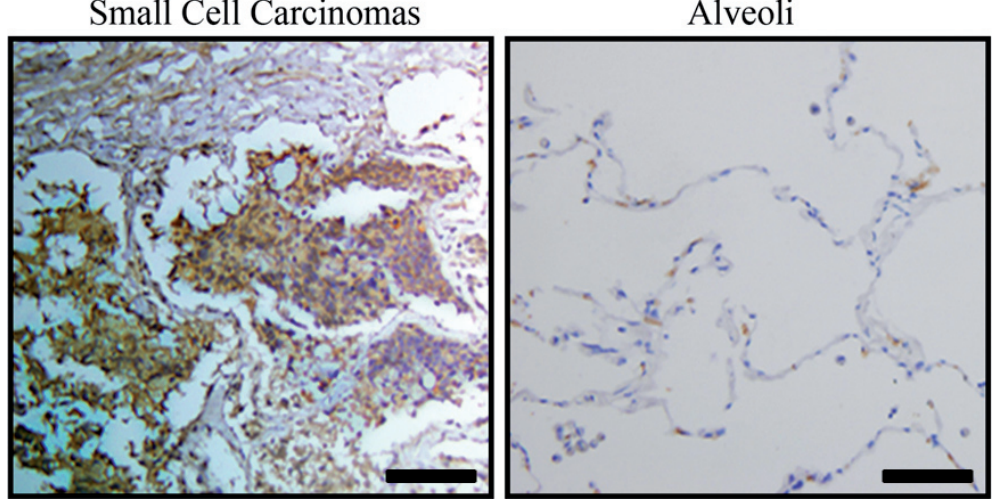

Figure 1. Immunohistochemistry for RhoGDIa. Examples of various lung cancer pathological types and areas of normal lung tissue stained with an anti-RhoGDIa antibody: squamous cell carcinoma, adenocarcinoma, small-cell carcinoma and alveoli. Immunostaining is observed in the areas of lung cancer tissue, but not obviously in the alveoli. Scale bar=50 $\mu \mathrm{m}$.

MTT assay. Cellular viability was evaluated by the MTT (3-[4,5-dimethyltiazol-2-yl] 2,5-diphenyl-tetrazolium bromide) assay [12]. Cells were seeded in 96-well tissue culture plates at concentrations of $5 \times 10^{3} /$ well. After treatment, MTT (Sigma, St. Louis, MO, USA) was added to each well at a final concentration of $0.5 \mathrm{mg} / \mathrm{ml}$, followed by incubation at $37^{\circ} \mathrm{C}$ for $4 \mathrm{~h}$. Then, the medium was removed and $200 \mu \mathrm{l}$ of dimethyl sulphoxide (DMSO) was added to each well. The absorbance of the mixture was measured at $490 \mathrm{~nm}$ using a microplate ELISA reader (Bio-Rad Laboratories). The relative cell viability was calculated as follows: relative cell viability $=($ mean experimental absorbance/mean control absorbance) $\times 100 \%$.

Apoptosis analysis. The apoptosis level was assessed by quantification of the sub- $G_{1}$ peak by flow cytometry (FCM). Briefly, adherent and detached cells were collected with trypsin, resuspended at $1 \times 10^{6} / \mathrm{mL}$ and fixed in ice-cold $70 \%$ ethanol for 4 hours at $4^{\circ} \mathrm{C}$. Each sample was resuspended in $\mathrm{PI} / \mathrm{RNase}$ solution for $30 \mathrm{~min}$ and analyzed using a fluorescence-activated cell sorter (FACS) (Beckman, Miami, USA). The relative level of apoptosis was calculated as follows: relative apoptosis $=$ (mean experimental apoptosis percentage $/$ mean control apoptosis percentage) $\times 100 \%$.
Statistical analysis. Statistical analysis was carried out using the SAS Statistical program version 8.2 for Windows. The association between RhoGDIa and the clinicopathological data was explored and assessed by the $\chi^{2}$ or Fisher's exact tests, depending on the cellular frequencies observed in the $2 \times 2$ tables. The correlations between the protein level of RhoGDIa and the phosphorylation levels of p-ERK, p-JNK, p-Akt, p-Bad and $\mathrm{p}$-I $\mathrm{KB} \alpha$ were assessed by Spearman's rank correlation coefficient. $\mathrm{P}<0.05$ was considered statistically significant.

\section{Results}

Expression of RhoGDIa in tissue specimens of patients with lung cancer. The level of RhoGDIa protein in 40 specimens of cancer tissue and 30 paired paracancerous tissue specimens from patients with lung cancer was assessed by IHC techniques. In the lung cancer specimens, high levels of RhoGDIa were observed in a variety of pathological types of lung cancer. In contrast, no obvious RhoGDIa immunoreactivity was identified in the alveoli (Fig. 1). The level of RhoGDIa positivity was significantly higher in lung cancer tissues than in paracancerous tissues (Table 1). An analysis by stratification for sex, age, pathological subtype, tumor 
Table 1. The expression of RhoGDIa in lung cancer tissue and para-tumor tissue.

\begin{tabular}{lcccc}
\hline & No. of patients & $\begin{array}{c}\text { Positive } \\
(\mathrm{n})\end{array}$ & $\begin{array}{c}\text { Negative } \\
(\mathrm{n})\end{array}$ & $\begin{array}{c}\text { Positive } \\
(\%)\end{array}$ \\
\hline Lung cancer tissue & 40 & 34 & 6 & 85 \\
Para-tumor tissue & 30 & 18 & 12 & 6.027 \\
\hline
\end{tabular}

Table 2. Clinicopathological features and their relationship to RhoGDIa staining.

\begin{tabular}{lccc}
\hline & $\begin{array}{c}\text { No. of } \\
\text { patients } \\
(\mathrm{n}=40)\end{array}$ & $\begin{array}{c}\text { The expression } \\
\text { of RhoGDIa } \\
(\%)\end{array}$ & $\mathrm{P}$ \\
$\quad$ Gender & 25 & 88 & 0.654 \\
$\quad$ Male & 15 & 80 & \\
$\quad$ Female & & & 1 \\
Age (yrs) & 14 & 85.7 & \\
$\quad \leq 60$ & 26 & 84.6 & \\
$\quad>60$ & & & 0.422 \\
Histology & 18 & 88.9 & \\
$\quad$ Squamous cell carcinoma & 16 & 75 & \\
$\quad$ Adenocarcinoma & 6 & 100 & \\
$\quad$ Small cell carcinoma & & & 1 \\
Tumor grading & 22 & 86.4 & \\
$\quad$ Well and intermediate differentiated & 18 & 83.3 & \\
$\quad$ Poor differentiated & & & 0.195 \\
Metastatic lymph nodes & 24 & 91.7 & \\
$\quad$ Positive & 16 & 75 & \\
$\quad$ Negative & & & 0.671 \\
Stage & 27 & 81.5 & \\
$\quad$ Early (I/II) & 13 & 92.3 & \\
$\quad$ Advanced (III/IV) & & & \\
\hline
\end{tabular}

grade, lymphatic metastasis, and TNM stage was performed, but RhoGDIa positivity was not significantly different within these stratification factors, although there was a trend toward increased RhoGDIa positivity in cases with metastatic lymph node involvement (Table 2).

Downregulation of RhoGDIa induces apoptosis in lung cancer cells. It has already been shown that RhoGDIa plays an important role in protecting tumor cells from apoptosis induction $[5,9,10]$. As RhoGDIa has been found to be overexpressed in lung cancer tissues, we assessed whether the knockdown of RhoGDIa could trigger apoptosis in lung cancer cells. Cells were divided into three treatment groups: solvent control (Control), control siRNA and RhoGDIa siRNA. Cells were initially treated for 24,48 , or 72 hours, and were then tested for the expression of RhoGDIa mRNA in A549 cells. RT-PCR analysis revealed decreased levels of RhoGDIa mRNA in the cells transfected with RhoGDIa siRNA for 24 and 48 hours (Fig. 2A). Western blot analysis revealed similar changes in the levels of RhoGDIa protein (Fig. 2B) in both A549 and H157 cells. Therefore, 48 hours was selected as the standard time for transfection in all further experiments.
A
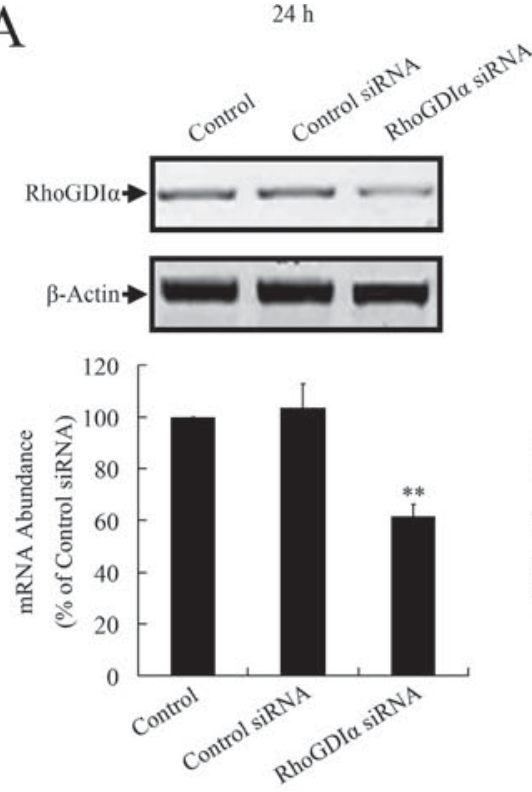

$48 \mathrm{~h}$
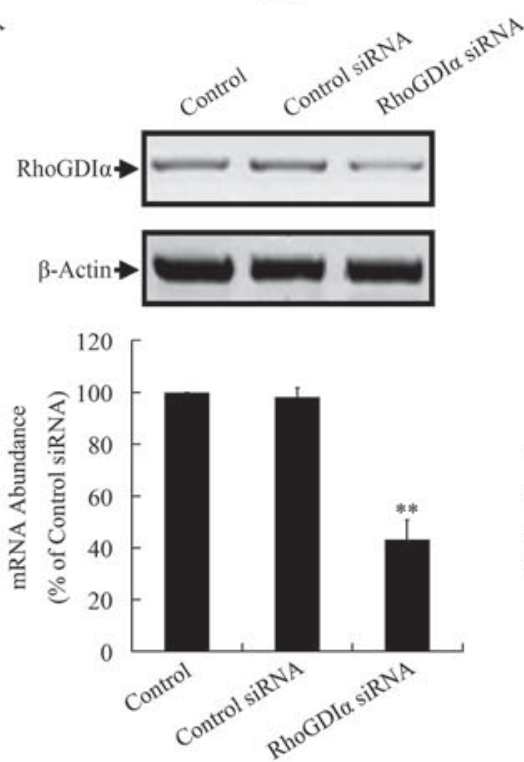

$72 \mathrm{~h}$
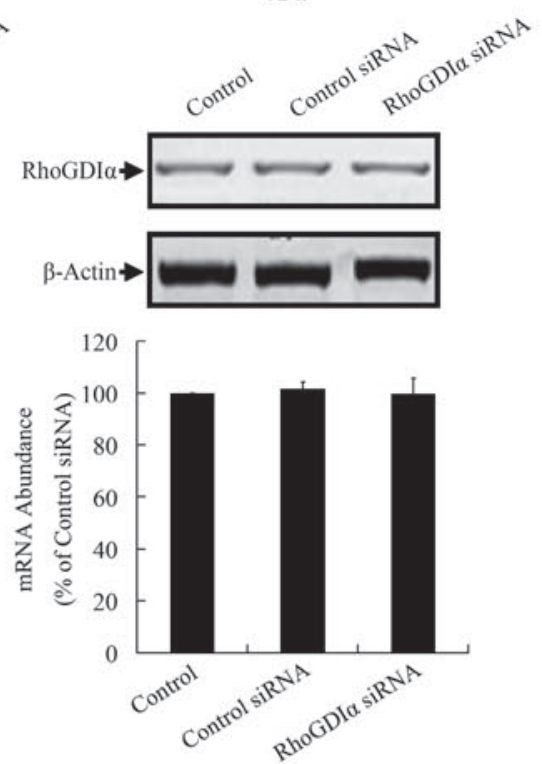

Figure 2. The role of RhoGDIa in tumor cell apoptosis and growth. (A) The expression of RhoGDIa mRNA was decreased in A549 cells transfected with RhoGDI $\alpha$ siRNA. Cells were transfected with RhoGDIa or Control siRNA for 24, 48, or 72 hours, and RhoGDIa mRNA was assayed by RT-PCR. 
$\mathrm{B}$
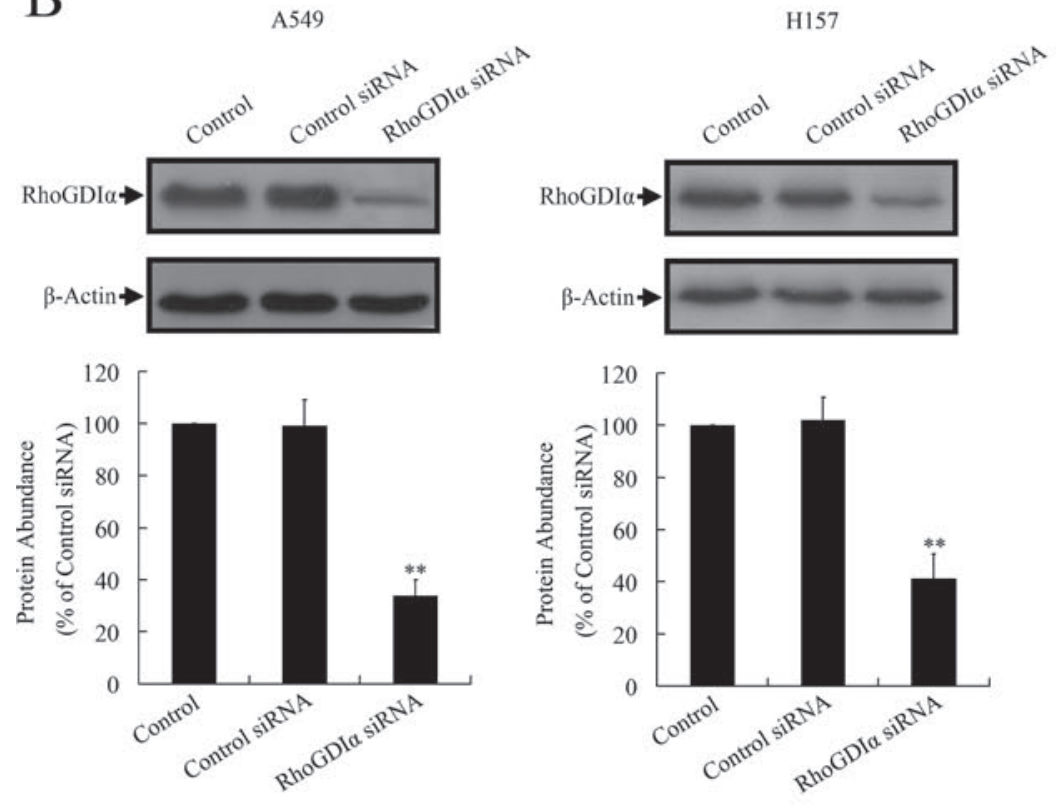

D

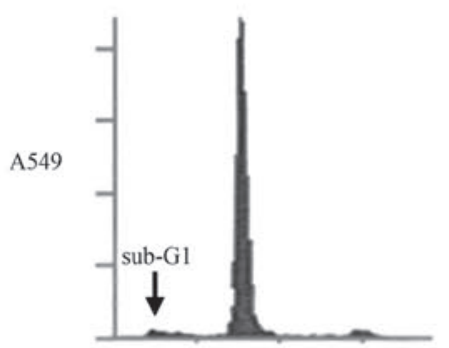

Control siRNA

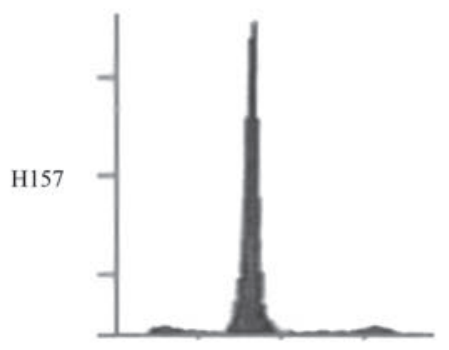

Control siRNA

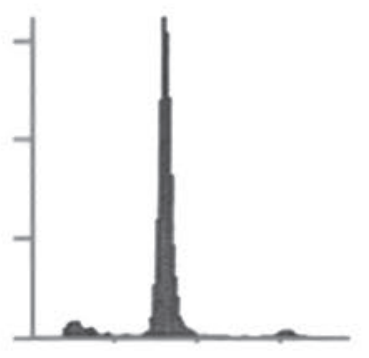

RhoGDI $\alpha$ siRNA

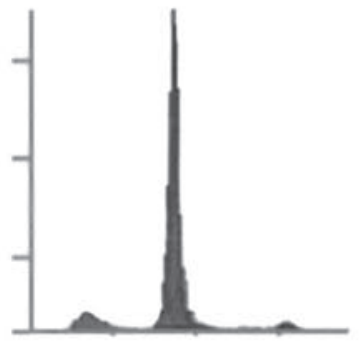

RhoGDI $\alpha$ siRNA
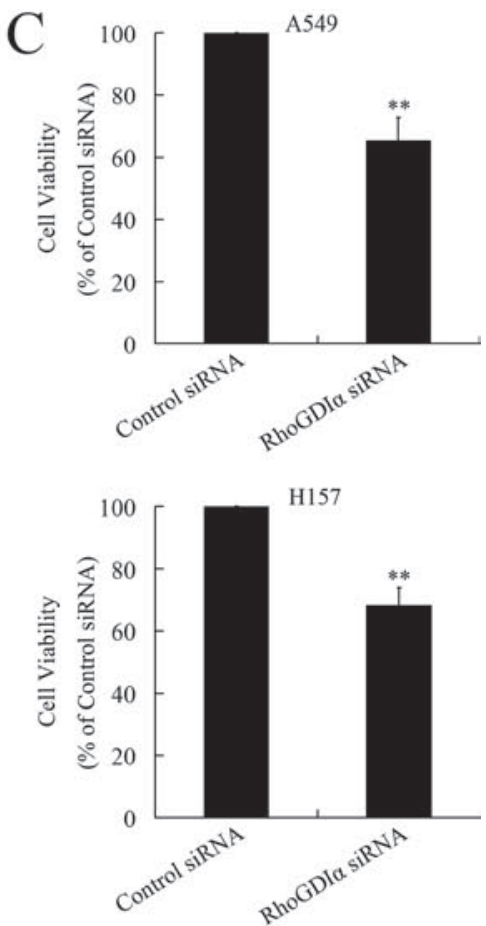
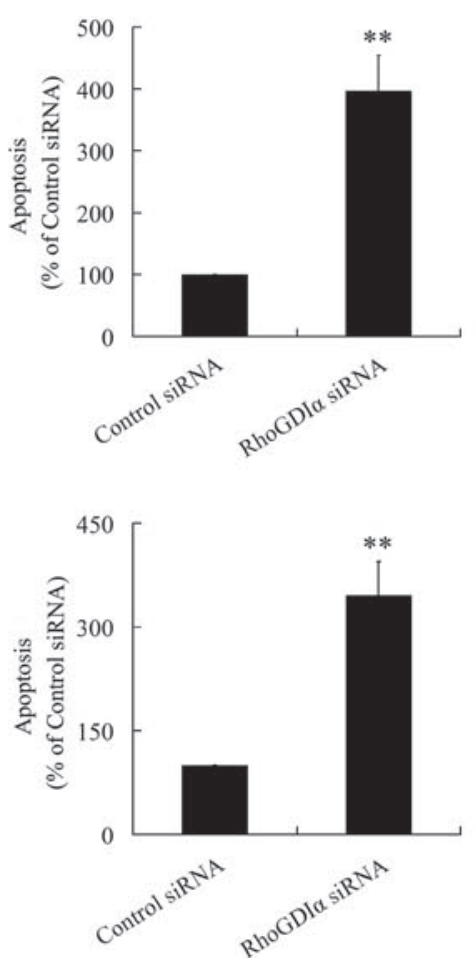

Figure 2. The role of RhoGDIa in tumor cell apoptosis and growth. (B) The expression of RhoGDIa protein was decreased in A549 and H157 cells transfected with RhoGDIa siRNA. After transfection for 48 hours, the lysates from A549 or H157 cells transfected with RhoGDIa or Control siRNA were analyzed by Western blotting. (C) Downregulation of RhoGDIa repressed cell viability in A549 and H157 cells. Viability of cells transfected with control siRNA and RhoGDI $\alpha$ siRNA for 48 hours were tested using MTT assay. RhoGDI $\alpha$ siRNA presented a significant repress on cell viability. ${ }^{*} \mathrm{P}<$ 0.01 indicate significant differences from the control siRNA group. (D) Knockdown of RhoGDIa triggered apoptosis in A549 and H157 cells; 48 hours after transfection cells were stained with PI for apoptosis analysis. RhoGDIa siRNA induced significant apoptosis in A549 and H157 cells. ${ }^{\star \star P}<0.01$ indicate significant differences from control siRNA group. 

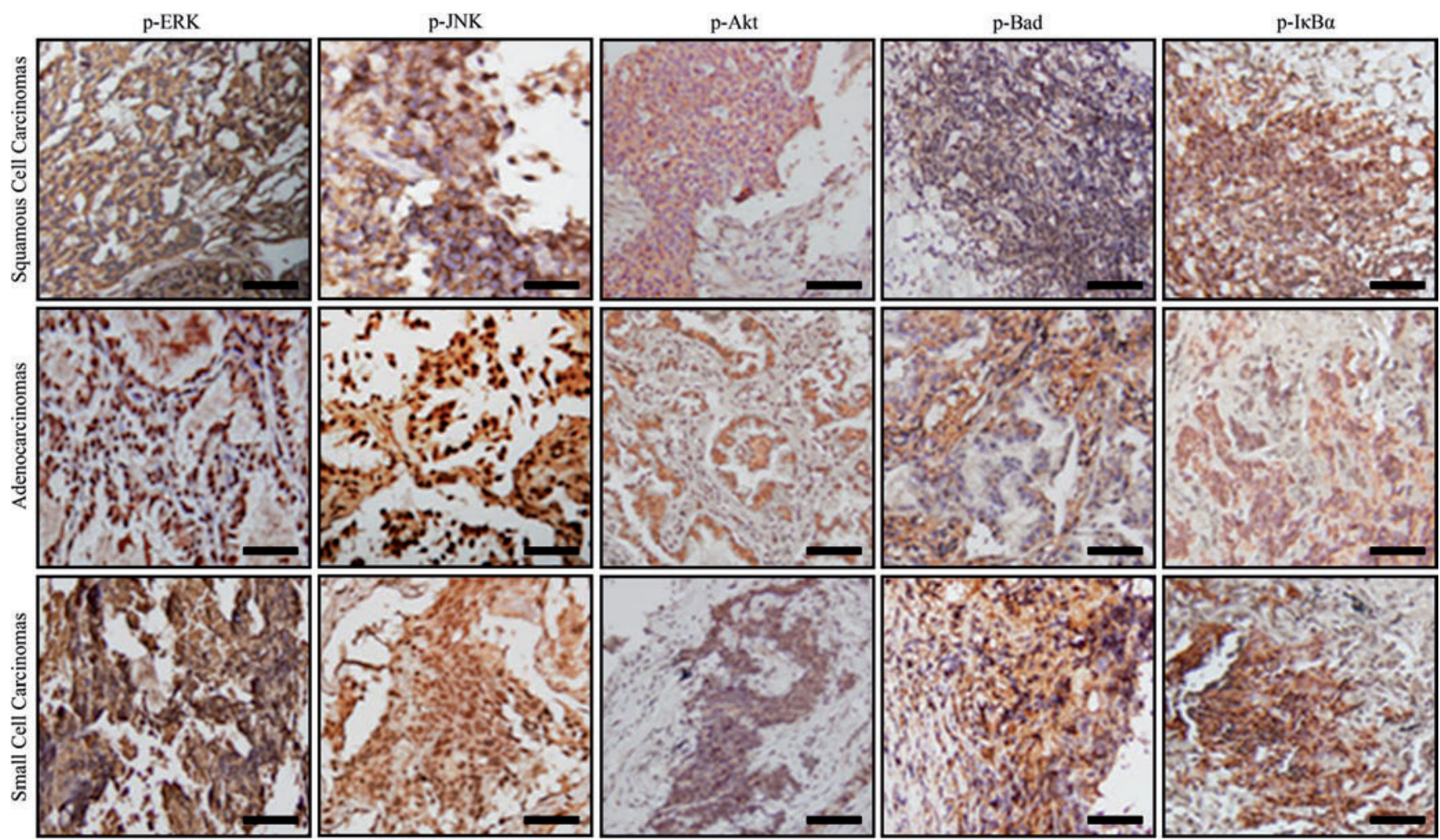

Figure 3. Phosphorylation levels of ERK, Akt, JNK, Bad and IкBa in sections of squamous cell carcinoma, adenocarcinoma and small-cell lung carcinoma. Scale bar $=50 \mu \mathrm{m}$.

MTT assays were applied to quantify the growth inhibition effect of RhoGDIa siRNA. As shown in Fig. 2C, the knockdown of RhoGDIa significantly repressed cell viability. The role of RhoGDIa downregulation on apoptosis in A549 and H157 cells was assessed by flow cytometry. Cells with downregulated levels of RhoGDIa exhibited a significantly higher level of apoptosis than the control siRNA groups (Fig. 2 D). These results indicate that downregulation of RhoGDIa induced apoptosis and repressed cell growth in lung cancer cells.

Relationships between the expression of RhoGDIa and the phosphorylation levels of apoptosis-relating proteins in lung cancer tissues. As RhoGDIa played a role in protecting cells from the induction of apoptosis, the mechanism of its action as an anti-apoptotic molecule was explored further. Several pathways have been proved to participate in the regulation of apoptosis, such as the MAPK [13], PI3K/Akt [14], Bcl-2 [15] and NF- $\kappa B$ pathways [16]. These pathways are down- stream of Rac-1 [17-22], which is a target of RhoGDIa [5]. Therefore, these pathways may be involved in the regulation of RhoGDIa-related apoptosis. To confirm this hypothesis, the phosphorylation levels of several proteins, including ERK, JNK, Akt, Bad and I $\kappa \mathrm{B} \alpha$, which are kinases that belong to these signaling pathways, were assessed in lung cancer tissues (Fig. 3). The correlations between RhoGDIa expression level and the phosphorylation levels of these signaling proteins were analyzed. IHC analysis revealed that the level of RhoGDIa protein was positively correlated with the phosphorylation levels of $\mathrm{Bad}(\mathrm{p}-\mathrm{Bad})$, and negatively correlated with $\mathrm{p}$-JNK (Table 3). No correlations were identified between the expression levels of RhoGDIa and the phosphorylation levels of other signaling proteins.

The effects of RhoGDIa knockdown on the phosphorylation levels of signaling proteins involved in apoptosis. To confirm the above observation in lung cancer specimens, we

Table 3. The relationship of RhoGDIa with p-ERK, p-Akt, p-Bad, p-JNK and p-IKBa.

\begin{tabular}{|c|c|c|c|c|c|c|c|c|c|c|}
\hline & \multicolumn{2}{|c|}{ p-ERK } & \multicolumn{2}{|c|}{ p-Akt } & \multicolumn{2}{|c|}{ p-Bad } & \multicolumn{2}{|c|}{ p-JNK } & \multicolumn{2}{|c|}{ p-ІкB $\alpha$} \\
\hline & $\mathrm{R}$ & $\mathrm{P}$ & $\mathrm{R}$ & $\mathrm{P}$ & $\mathrm{R}$ & $\mathrm{P}$ & $\mathrm{R}$ & $\mathrm{P}$ & $\mathrm{R}$ & $\mathrm{P}$ \\
\hline RhoGDIa & 0.135 & 0.405 & 0.196 & 0.225 & 0.459 & $0.003^{* *}$ & -0.336 & $0.034^{\star}$ & 0.116 & 0.478 \\
\hline
\end{tabular}

$\mathrm{R}$, rank correlation coefficient; ${ }^{*} \mathrm{P}<0.05,{ }^{* *} \mathrm{P}<0.01$. 
then evaluated the effects of the RhoGDIa knockdown on the phosphorylation levels of apoptosis-relating proteins in A549 cells using Western blotting (Fig. 4). Upon the downregulation of RhoGDIa, the level of p-JNK increased, the level of p-Bad decreased, and the level of p-Akt was unchanged, which was in accordance with the observations in lung cancer tissues. Although we found no relationships between RhoGDIa expression and $\mathrm{p}$-I $\mathrm{KB} a$ or $\mathrm{p}$-ERK in the IHC analysis, the downregulation of RhoGDIa in A549 cells increased the levels of I $\mathrm{KB} \alpha$ and ERK phosphorylation significantly, which suggests that these two pathways could also be involved in the regulation of apoptosis by RhoGDIa.

Downregulation of RhoGDIa sensitizes A549 cells to apoptosis induced by paclitaxel. Paclitaxel, a microtubule inhibitor, is one of the most effective chemotherapeutic agents against lung cancer. The mechanism of the anticancer action of paclitaxel involves inducing mitotic arrest of the cells due to microtubule stabilization, which eventually results in apoptosis $[23,24]$. Unfortunately, the emergence of chemoresistance is a major obstacle in paclitaxel treatment. As RhoGDIa could protect NSCLC cells from the induction of apoptosis, we ascertained whether the knockdown of RhoGDIa could sensitize NSCLC cells to the treatment of paclitaxel.

Following $10 \mathrm{nM}$ paclitaxel treatment for 24 hours, the level of apoptosis was quantified by FCM. Treatment with paclitaxel led to a 2.12 -fold $( \pm 0.09)$ increase in the level of apoptosis in the control siRNA-transfected groups, compared to cells transfected with RhoGDIa siRNA, where paclitaxel results in 3.04-fold ( \pm 0.21 ) higher levels of apoptosis (Fig. 5A).

The MTT assays further confirmed the increase of paclitaxel cytotoxicity against cell viability when RhoGDIa was knocked down. In the control siRNA-treated groups, paclitaxel repressed cell viability by $25.67 \% \pm 10.07 \%$. In the RhoGDIa siRNA-treated groups, the decrease in cell viability after paclitaxel treatment was $52.12 \% \pm 10.84 \%$ (Fig. 5B).

In order to investigate the mechanism involved in the chemosensitization effect of RhoGDIa siRNA, the phosphorylation levels of the signaling proteins, including ERK, JNK, Akt, Bad and IкBa, were assessed by Western blotting. When treated with paclitaxel for 24 hours, the phosphorylation level of JNK, I $\kappa \mathrm{B} \alpha, \mathrm{Bad}$ and ERK increased. Downregulation of RhoGDI $\alpha$ reduced the upregulation of $\mathrm{p}-\mathrm{I} \mathrm{K} \mathrm{B} \alpha, \mathrm{p}-\mathrm{Bad}$ and p-ERK induced by paclitaxel, but increased the paclitaxelstimulated upregulation of p-JNK (Fig. 5C). These results indicate that the downregulation of RhoGDIa may sensitize A549 cells to paclitaxel-induced apoptosis through diminishing the phosphorylation of IKB $\alpha, \mathrm{Bad}$ and ERK, and increasing the activation of JNK.

\section{Discussion}

RhoGDIa, a member of the GDI family, is involved in a variety of cellular processes that include cell differentiation, cytoskeletal rearrangement and apoptosis [3]. Recent studies have shown that the level of RhoGDIa expression is increased

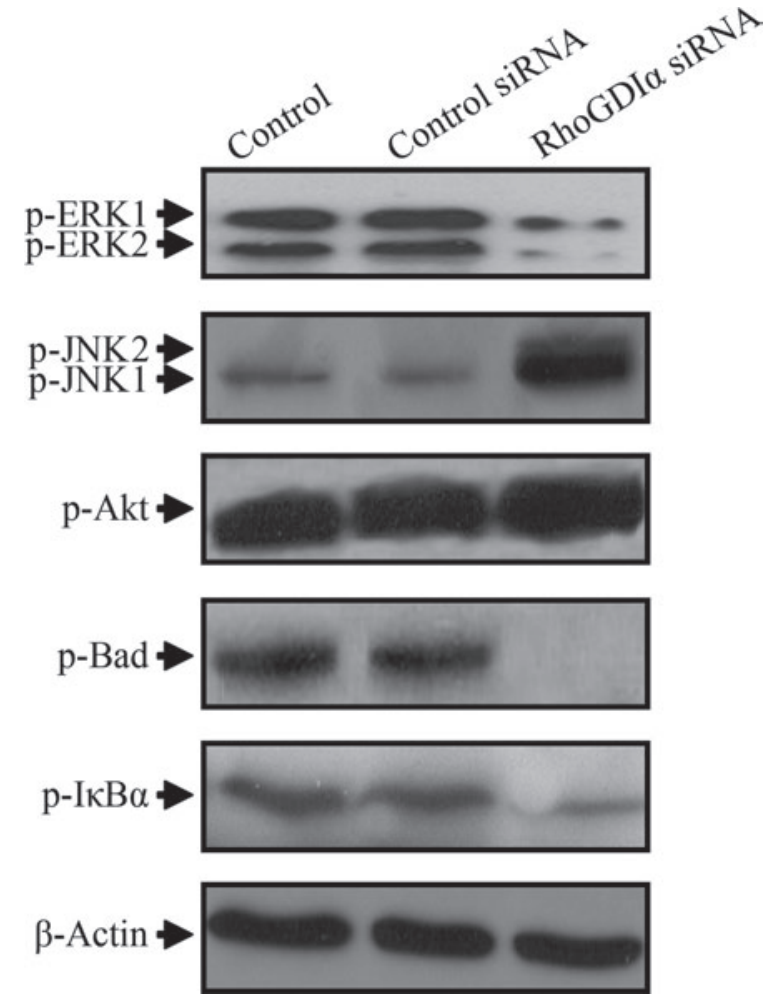

Figure 4. The changes in the phosphorylation levels of the signaling proteins involved in apoptosis. Cells were divided into three treatment groups: solvent control (Control), control siRNA and RhoGDIa siRNA. The lysates from A549 cells were assayed by Western blotting $48 \mathrm{~h}$ after transfection.

in various cancers, including ovarian [6] and breast cancer [7]. Some studies have even demonstrated that the degree of RhoGDIa overexpression correlates with cancer grade [6] and drug resistance in vitro [9]. This study has shown that the inhibition of RhoGDIa by targeted siRNA led to the induction of apoptosis and the inhibition of growth in lung cancer cells. These results show that the downregulation of RhoGDIa induced apoptosis in cancer cells and suggest that RhoGDIa plays an important role in protecting lung cancer cells from apoptosis. However, the cell signaling transduction mechanism involved in the RhoGDIa-related regulation of apoptosis remains unclear.

Upon treatment with chemotherapeutics, RhoGDIa can form a tight complex with the Racl GTPase in the cytoplasm, which may shield Rac1 from caspase-mediated cleavage, thus maintaining Rac1 in an intact and functional state [5]. Rac1 inhibits apoptosis, as well as promote cancer cell proliferation and metastasis through the phosphorylation of Bad [21], ERK [17] JNK [18, 19], Akt [20] and IкBa [22]. The RhoGDIa-dependent inhibition of apoptosis might be executed through the phosphorylation of these proteins. Thus, the relationships between the expression of RhoGDIa and the phosphorylation levels of Bad, ERK, JNK, Akt and IкBa were assayed in this study. 
A

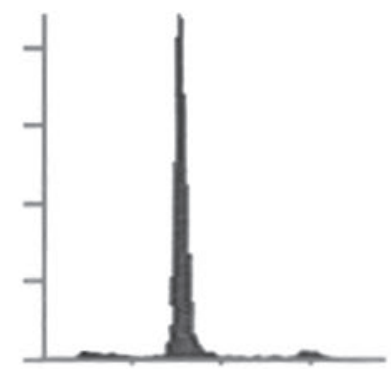

Control siRNA

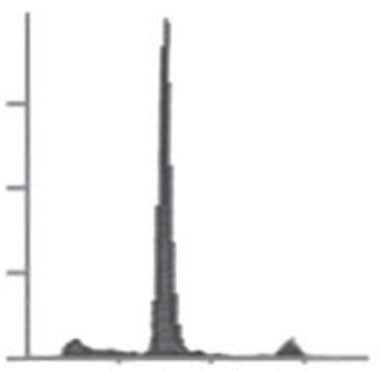

RhoGDI $\alpha$ siRNA
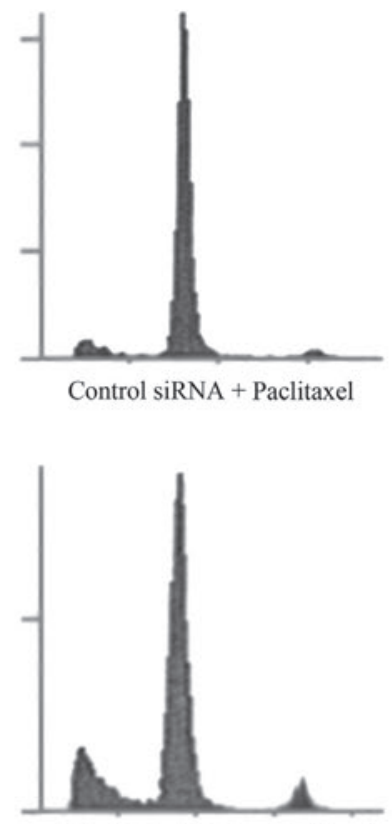

RhoGDI $\alpha$ siRNA + Paclitaxel
B

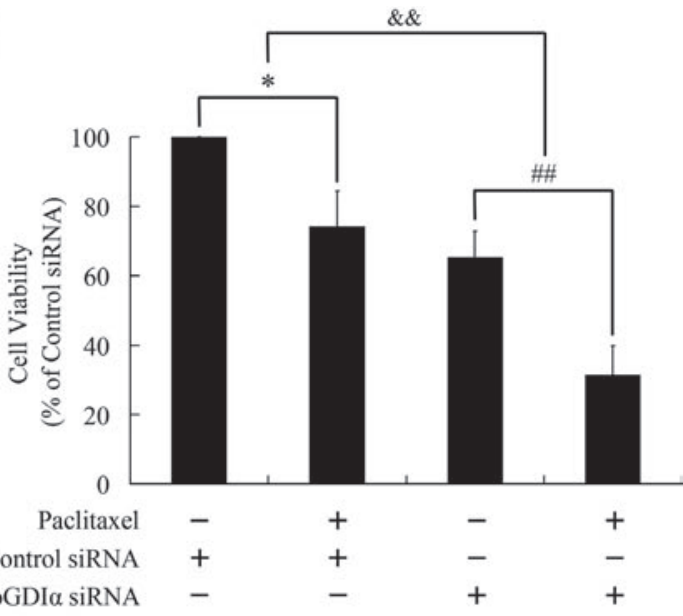

$\mathrm{C}$

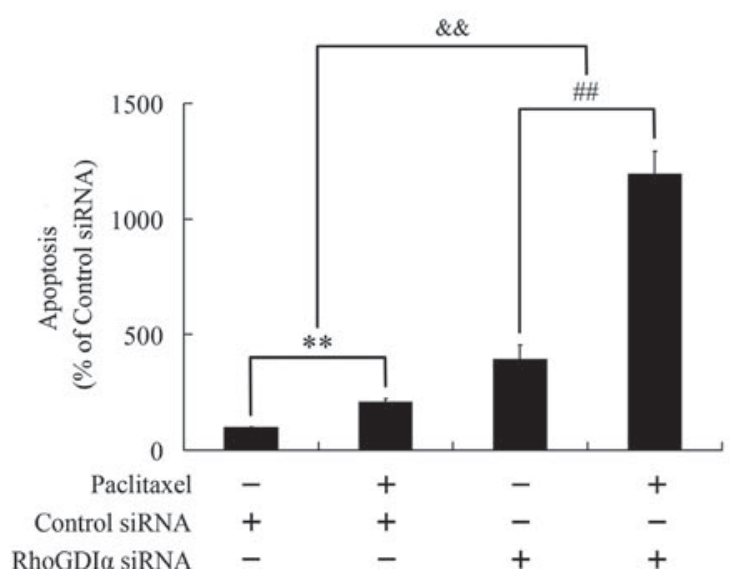

Figure 5. The role of RhoGDIa in paclitaxel-induced apoptosis and growth inhibition. (A) and (B) Downregulation of RhoGDIa increased the sensitivity of cells to paclitaxel-induced apoptosis (A) and growth inhibition (B). After transfection with control siRNA or RhoGDIa siRNA for 48 hours, cells were further treated with $10 \mathrm{nM}$ paclitaxel for 24 hours followed by apoptosis assay using flow cytometry or cell viability evaluation using MTT assay. ${ }^{\star} P<0.05$ and ${ }^{\star \star} P<0.01$ vs. control siRNA group; ${ }^{\# \#} P<0.01$ vs. RhoGDIa siRNA group; ${ }^{* \&} P<0.01$ between folds induction. (D) The changes in the phosphorylation levels of the signaling proteins involved in apoptosis. After transfection with control siRNA or RhoGDIa siRNA for 48 hours, cells were further treated with $10 \mathrm{nM}$ paclitaxel for 24 hours. The lysates from A549 cells were assayed by Western blotting.

Figures 3 and 4 show that RhoGDIa expression levels positively correlated with those of p-Bad, p-ERK and pIкBa. Considering the anti-apoptotic effect of p-Bad [25], p-ERK [26] and p-IкBa [22], RhoGDIa potentially inhibits apoptosis through the phosphorylation of these three proteins. Interestingly, a negative correlation was found between RhoGDIa expression levels and p-JNK. The reason for this might be due to the complex function of JNK, the activation of which can promote proliferation [27] or induce apoptosis $[28,29]$, depending on the stimulation and cell type. As JNK-dependent induction of apoptosis has been widely explored in lung cancer cells $[29,30]$, the activation of JNK in the lung cancer tissues and cells used in this study could to be pro-apoptotic. Therefore, the upregulation of RhoGDIa might repress apoptosis through the inhibition of JNK. 
It has been previously shown that RhoGDIa protects breast cancer cells against apoptosis induced by treatment with etoposide (VP-16) and doxorubicin [5]. In the present study, the downregulation of RhoGDIa using siRNA appeared to sensitize A549 cells to paclitaxel treatment, which is a drug in common use for the treatment of lung cancer. These studies suggested that the combination of RhoGDIa knockdown could be a promising strategy for chemotherapy.

Paclitaxel induces apoptosis through the activation of JNK [31], while the phosphorylation of ERK [32,33], Bad [34] and IкBa [35] results in paclitaxel resistance. Our study revealed that treatment with paclitaxel increased the phosphorylation levels of JNK, IKBa, Bad and ERK, which was in line with previous studies. These observations suggested that the phosphorylation of JNK mediated cytotoxicity, but the phosphorylation of ERK, Bad and I $\mathrm{BB} a$ reduced the curative effect of paclitaxel. Moreover, knocking down RhoGDIa increased the phosphorylation of JNK, but prevented the up-regulation of $\mathrm{p}$-ERK, $\mathrm{p}$-Bad and $\mathrm{p}$-I $\mathrm{K} \mathrm{B} \alpha$, suggesting the downregulation of RhoGDIa could enhance JNK-dependent induction of apoptosis and decrease the ERK, Bad and IкBa-dependent protection. These results indicate that the chemosensitization effect of RhoGDIa siRNA to paclitaxel could be a result of the increase in the induction of apoptosis, in addition to reducing levels of chemoresistance.

In summary, we have shown that RhoGDIa was overexpressed in lung cancer tissue. RhoGDIa protected cells from apoptosis. This effect could be due to the phosphorylation of ERK, Bad and IkBa, as well as the dephosphorylation of JNK. The knockdown of RhoGDIa induced apoptosis and repressed cell viability, which suggests that RhoGDIa might be a new therapeutic target for lung cancer. Moreover, the knockdown of RhoGDIa sensitized lung cancer cells to the cytotoxic effects of paclitaxel. This chemosensitization effect could be due to the repression of the anti-apoptotic factors, p-ERK, p-Bad and p-IkBa, as well as the upregulation of the pro-apoptotic protein, p-JNK. Thus, the combination of RhoGDIa siRNA and paclitaxel might be an effective strategy for lung cancer treatment.

Acknowledgments: This work was supported by the program for Changjiang Scholars and Innovative Research Team in University (IRT0849); China International Medical Foundation (CIMFF-H001-057); the National Natural Science Foundation of China (No. 81101867); the Science and Education for Health foundation of Suzhou for Youth (SWKQ1003).

\section{References}

[1] JEMAL A, SIEGEL R, XU J, WARD E. Cancer statistics, 2010. CA Cancer J Clin 2010; 60: 277-300. http://dx.doi. org/10.3322/caac. 20073

[2] RAEZ LE, KOBINA S, SANTOS ES. Oxaliplatin in first-line therapy for advanced non-small-cell lung cancer. Clin Lung Cancer 2010; 11: 18-24. http://dx.doi.org/10.3816/CLC.2010. $\underline{\text { n.003 }}$
[3] ADRA CN, IYENGAR AR, SYED FA, KANAAN IN, RILO HL et al. Human ARHGDIG, a GDP-dissociation inhibitor for Rho proteins: genomic structure, sequence, expression analysis, and mapping to chromosome 16p13.3. Genomics 1998; 53: 104-109. http://dx.doi.org/10.1006/geno.1998.5482

[4] AROZARENA I, MATALLANAS D, CRESPO P. Maintenance of CDC42 GDP-bound state by Rho-GDI inhibits MAP kinase activation by the exchange factor Ras-GRF. evidence for RasGRF function being inhibited by Cdc42-GDP but unaffected by CDC42-GTP. J Biol Chem 2001; 276: 21878-21884. http:// dx.doi.org/10.1074/jbc.M011383200

[5] ZHANG B, ZHANG Y, DAGHER MC, SHACTER E. Rho GDP dissociation inhibitor protects cancer cells against drug-induced apoptosis. Cancer Res 2005; 65: 6054-6062. http://dx.doi.org/10.1158/0008-5472.CAN-05-0175

[6] JONES MB, KRUTZSCH H, SHU H, ZHAO Y, LIOTTA LA et al. Proteomic analysis and identification of new biomarkers and therapeutic targets for invasive ovarian cancer. Proteomics 2002; 2: 76-84. http://dx.doi.org/10.1002/16159861(200201)2:1<76::AID-PROT76>3.0.CO;2-O

[7] HONDERMARCK H, VERCOUTTER-EDOUART AS, REVILLION F, LEMOINE J, EL-YAZIDI-BELKOURA I et al. Proteomics of breast cancer for marker discovery and signal pathway profiling. Proteomics 2001; 1: 1216-1232. http://dx.doi.org/10.1002/1615-9861(200110)1:10<1216:: AID-PROT1216>3.0.CO;2-P

[8] FRITZ G, BRACHETTI C, BAHLMANN F, SCHMIDT M, KAINA B. Rho GTPases in human breast tumours: expression and mutation analyses and correlation with clinical parameters. Br J Cancer 2002; 87: 635-644. http://dx.doi. org/10.1038/sj.bjc. 6600510

[9] POLAND J, SCHADENDORF D, LAGE H, SCHNOLZER M, CELIS JE et al. Study of therapy resistance in cancer cells with functional proteome analysis. Clin Chem Lab Med 2002; 40: 221-234. http://dx.doi.org/10.1515/CCLM.2002.037

[10] JONESON T, BAR-SAGI D. Suppression of Ras-induced apoptosis by the Rac GTPase. Mol Cell Biol 1999; 19: 58925901.

[11] BURKE L, FLIEDER DB, GUINEE DG, BRAMBILLA E, FREEDMAN AN et al. Prognostic implications of molecular and immunohistochemical profiles of the $\mathrm{Rb}$ and $\mathrm{p} 53$ cell cycle regulatory pathways in primary non-small cell lung carcinoma. Clin Cancer Res 2005; 11: 232-241.

[12] CARMICHAEL J, DEGRAFF WG, GAZDAR AF, MINNA JD, MITCHELL JB. Evaluation of a tetrazolium-based semiautomated colorimetric assay: assessment of chemosensitivity testing. Cancer Res 1987; 47: 936-942.

[13] MACCORKLE RA, TAN TH. Mitogen-activated protein kinases in cell-cycle control. Cell Biochem Biophys 2005; 43: 451-461. http://dx.doi.org/10.1385/CBB:43:3:451

[14] SONG G, OUYANG G, BAO S. The activation of Akt/PKB signaling pathway and cell survival. J Cell Mol Med 2005; 9: 59-71. http://dx.doi.org/10.1111/j.1582-4934.2005.tb00337. $\underline{x}$

[15] YOULE RJ, STRASSER A. The BCL-2 protein family: opposing activities that mediate cell death. Nat Rev Mol Cell Biol 2008; 9: 47-59. http://dx.doi.org/10.1038/nrm2308 
[16] INOUE J, GOHDA J, AKIYAMA T, SEMBA K. NF-kappaB activation in development and progression of cancer. Cancer Sci 2007; 98: 268-274. http://dx.doi.org/10.1111/j.13497006.2007.00389.x

[17] YANG C, KLEIN EA, ASSOIAN RK, KAZANIETZ MG. Heregulin beta1 promotes breast cancer cell proliferation through Rac/ERK-dependent induction of cyclin D1 and p21Cip1. Biochem J 2008; 410: 167-175. http://dx.doi. org/10.1042/BJ20070781

[18] GRIJELMO C, RODRIGUE C, SVRCEK M, BRUYNEEL E, HENDRIX A. Proinvasive activity of BMP-7 through SMAD4/src-independent and ERK/Rac/JNK-dependent signaling pathways in colon cancer cells. Cell Signal 2007; 19: 1722-1732. http://dx.doi.org/10.1016/j.cellsig.2007.03.008

[19] YU M, LUO J, YANG W, WANG Y, MIZUKI M et al. The scaffolding adapter Gab2, via Shp-2, regulates kit-evoked mast cell proliferation by activating the Rac/JNK pathway. J Biol Chem 2006; 281: 28615-28626. http://dx.doi.org/10.1074/jbc. $\underline{\mathrm{M} 603742200}$

[20] FUKUYAMA R, FUJITA T, AZUMA Y, HIRANO A, NAKAMUTA $H$ et al. Statins inhibit osteoblast migration by inhibiting Rac-Akt signaling. Biochem Biophys Res Commun 2004; 315 : 636-642. http://dx.doi.org/10.1016/j.bbrc.2004.01.104

[21] ZHANG B, ZHANG Y, SHACTER E. Rac1 inhibits apoptosis in human lymphoma cells by stimulating Bad phosphorylation on Ser-75. Mol Cell Biol 2004; 24: 6205-6214. http://dx.doi. org/10.1128/MCB.24.14.6205-6214.2004

[22] PERONA R, MONTANER S, SANIGER L, SANCHEZ-PEREZ I, BRAVO R et al. Activation of the nuclear factor-kappaB by Rho, CDC42, and Rac-1 proteins. Genes Dev 1997; 11: 463-475. http://dx.doi.org/10.1101/gad.11.4.463

[23] BLAGOSKLONNY MV, FOJO T. Molecular effects of paclitaxel: myths and reality (a critical review). Int J Cancer 1999; 83: 151-156. http://dx.doi.org/10.1002/(SICI)10970215(19991008)83:2<151::AID-IJC1>3.0.CO;2-5

[24] MILLER ML, OJIMA I. Chemistry and chemical biology of taxane anticancer agents. Chem Rec 2001; 1: 195-211. http:// dx.doi.org/10.1002/tcr.1008

[25] DATTA SR, KATSOV A, HU L, PETROS A, FESIK SW et al. 14-3-3 proteins and survival kinases cooperate to inactivate BAD by BH3 domain phosphorylation. Mol Cell 2000; 6: 41-51.

[26] KIM JH, JEONG SJ, KIM B, YUN SM, CHOI DY et al. Melatonin synergistically enhances cisplatin-induced apoptosis via the dephosphorylation of ERK/p90 ribosomal S6 kinase/heat shock protein 27 in SK-OV-3 cells. J Pineal Res 2011; Epub ahead of print.

[27] POTAPOVA O, GOROSPE M, BOST F, DEAN NM, GAARDE WA et al. c-Jun N-terminal kinase is essential for growth of human T98G glioblastoma cells. J Biol Chem 2000; 275: 24767-24775. http://dx.doi.org/10.1074/jbc.M904591199

[28] SHEN HM, LIU ZG: JNK signaling pathway is a key modulator in cell death mediated by reactive oxygen and nitrogen species. Free Radic Biol Med 2006; 40: 928-939. http://dx.doi. org/10.1016/j.freeradbiomed.2005.10.056

[29] WU N, GU C, GU H, HU H, HAN Y et al. Metformin induces apoptosis of lung cancer cells through activating JNK/p38 MAPK pathway and GADD153. Neoplasma 2011; 58: 482-490. http://dx.doi.org/10.4149/neo 2011_06 482

[30] KANNAIYAN R, MANU KA, CHEN L, LI F, RAJENDRAN P et al. Celastrol inhibits tumor cell proliferation and promotes apoptosis through the activation of c-Jun $\mathrm{N}$-terminal kinase and suppression of PI3 K/Akt signaling pathways. Apoptosis 2011; 16: 1028-1041. http://dx.doi.org/10.1007/s10495-011-0629-6

[31] SELIMOVIC D, HASSAN M, HAIKEL Y, HENGGE UR. Taxol-induced mitochondrial stress in melanoma cells is mediated by activation of c-Jun N-terminal kinase (JNK) and p38 pathways via uncoupling protein 2. Cell Signal 2008; 20: 311-322. http://dx.doi.org/10.1016/j.cellsig.2007.10.015

[32] SUYAMA H, IGISHI T, SANO H, MATSUMOTO S, SHIGEOKA Y et al. ERK activation and subsequent RB phosphorylation are important determinants of the sensitivity to paclitaxel in lung adenocarcinoma cells. Int J Oncol 2004; 24: 1499-1504.

[33] OH SY, SONG JH, GIL JE, KIM JH, YEOM YI et al. ERK activation by thymosin-beta-4 (TB4) overexpression induces paclitaxel-resistance. Exp Cell Res 2006; 312: 1651-1657. http://dx.doi.org/10.1016/j.yexcr.2006.01.030

[34] SZANTO A, BOGNAR Z, SZIGETI A, SZABO A, FARKAS L et al. Critical role of bad phosphorylation by Akt in cytostatic resistance of human bladder cancer cells. Anticancer Res 2009; 29: 159-164.

[35] CAICEDO-GRANADOS EE, WUERTZ BR, MARKER PH, LEE GS, ONDREY FG The effect of indomethacin on paclitaxel sensitivity and apoptosis in oral squamous carcinoma cells: the role of nuclear factor-kappaB inhibition. Arch Otolaryngol Head Neck Surg 2011; 137: 799-805. http:// dx.doi.org/10.1001/archoto.2011.131 